\title{
Debate, Research and Critique in Contemporary Youth Studies
}

\author{
Hernan Cuervo ${ }^{1} \cdot$ Bronwyn E. Wood $^{2} \cdot$ Rob White $^{3}$
}

Published online: 27 June 2020

(C) Springer Nature Singapore Pte Ltd. 2020

We are delighted to mark this first issue which represents the return of the Journal of Applied Youth Studies (JAYS) to the arena of youth research and practice debates. JAYS was founded by former members of the Australian Clearinghouse for Youth Studies, on a completely volunteer basis, and was hosted by the Centre for Applied Youth Research in partnership with the Asia Institute Tasmania at the University of Tasmania. The journal filled the enormous gap left by the discontinuation of the publication of Youth Studies Australia, which had been documenting the lives of young people since 1981/1982. Under the previous editorial leadership, JAYS presented articles from all corners of the world with special focus on the Asia Pacific region. The new JAYS is published under Springer Nature and continues this inclusion of contemporary research from colleagues across the globe.

The journal is primarily anchored on sociological approaches to youth studies research; however, it also welcomes interdisciplinary original research on issues that concern youth and young adulthood, such as education, labour, transitions, subculture, social policy, crime, justice, wellbeing, family, housing, urban and rural, youth work, citizenship, political participation, migration, mobility, multiculturalism and digital technologies and social media. It also invites contributions from those who work directly with youth people, such as youth and community workers. Importantly, in JAYS we aim to centre on youth and young adults' lives rather than being a sideshow of other fields or used as the background, sample or merely context to a research study. The articles profiled in this issue illustrate this well with manuscripts which take as their central focus youth gangs (Feixa, Sanchez Garcia and Brisley), homeless youth (Cooper and Brooker) and possible futures for disadvantaged young people (Lindegaard Moensted), and significant issues youth experience focusing on transitions to work (Roberts), and into housing (Cook). These articles contribute to the growing

Hernan Cuervo

hicuervo@unimelb.edu.au

1 University of Melbourne, Melbourne Australia

2 Victoria University of Wellington, Wellington New Zealand

3 University of Tasmania, Hobart Australia 
and diverse international field of youth studies, providing insights that enhance not only understandings of youth but also policy and practice implications in sectors such as social welfare, education, employment and health.

As the name suggests, the Journal of Applied Youth Studies is interested in the application of youth studies - because we believe not only that there is nothing so practical as a good theory (Lewin, 1976, p. 169) but that the application of theoretical, empirical and conceptual ideas together serve to enrich youth studies. This has shaped our perspectives on the type of papers we are seeking for this journal. We are specifically interested in manuscripts that focus on the following:

- The application of theory into youth studies

- The application and interrogation of methodologies for the study of youth and how these shape up differently if we take the lives and experiences of young people seriously

- The application of policy analysis to examine youth as a political and economic construct

- The application of key youth studies themes, such as transition, culture, identity, belonging, mobility and citizenship, into various contexts and how these deepen our understandings of what it means to be young

- The application of theory into practice, particularly in the areas of youth, community and social work, and how research-led evidence can explain and improve youth and young adults' lives

The journal aims to contribute to deeper understandings of youth, youth theory, youth methodologies, youth policy and youth practices and, therefore, critically engages with research that serves to address inequalities and explain social change, as well as provide transformative insights into youth lives and those who work with them. This includes leading research and scholarship from sociology and different disciplines such as education, social work, criminology, political science, anthropology, health and wellbeing, geography, Indigenous studies, social policy and cultural studies. The experiences, research, evaluations and reflections provided by practitioners are important as well.

There is a significant need for more youth-related research, not least because the circumstances facing youth have become considerably more complex-even within the past couple of years. Over the last decade, young people and young adults worldwide have experienced two global financial recessions, with the subsequent growth of youth unemployment and underemployment; a global pandemic; increasing risks from climate change-related events; have been subject to state violence; and affected by civil war, including being forced to leave their homes and seek asylum. While these issues can affect all segments of the population, it is in many instances the young that suffer the most. For example, as we continue to grapple with the consequences of the spread of COVID-19 around the globe, it is in many instances the young people, due to their location in the labour market, that are impacted more heavily in terms of loss of jobs and income which enable them to construct a life. These challenges and risks, of course, continue to reveal persistent patterns of structural inequality. Social divisions such as class, gender, race, ethnicity, sexuality and place continue to shape the life opportunities and outcomes for youth. 
Yet we have also witnessed in this last decade youth and young adults at the forefront of political and social demonstrations to change the social order, such as in the Arab Spring, in the March for Our Lives protest against gun violence in the USA and through the climate change demonstrations across the globe. In many societies, particularly throughout the Western World, young people continue to invest in education and have become in many instances the most educated generation of their country's history. Youth and young adults are also at the vanguard of new ways of participating in society, including through digital platforms, as well as contesting traditional forms of relationships and advancing new ways of family formation. It seems important then to us that those involved in researching youth and young adulthood are offered ample opportunities and spaces to continue their engagement to critically understand and document these complex times.

In JAYS we wish to continue the important debates emanating from the field in the last few decades. Some of these debates have previously played out in this journal, for example, the valorisation of youth work practices against the pernicious effects on epistemology from systems of modernisation and rational governance of human services such as New Public Management (Sercombe, 2015), careful policy analysis to the complex issue of youth employment (Denny \& Churchill, 2016) and longitudinal youth transition approaches that defy the dominated focus from the global North (Bendit \& Miranda, 2016). Our journal will continue to be informed by many key debates and research contributions of youth studies scholars. In this renewed JAYS, we are interested in continuing the strong and vibrant tradition of youth scholarship built upon new understandings of the meaning and experience of youth that challenge developmental approaches that homogenise young people's lives, sharp analysis of the production of new youth subjectivities as those that emerged from a gender perspective or those that connect education to imagined youth future selves and robust policy analysis that illuminate the relationship between the state and young people. We look forward to receiving manuscripts that engage with the transition and cultural approaches, as well as original research that focus on the new frameworks of belonging, mobility, citizenship and political economy that contribute to explain and examine the ways young people make a life. We seek to publish research that focus on traditional social divisions, such as class, that help us understand the way that inequalities are structured, as well as analysis that makes visible the way other social divisions shape opportunities and barriers on youth lives. Importantly, we seek to continue building the rich body of research that focuses on understanding and analysing the experiences of the majority of the global youth which is located in the Global South to construct new theoretical and practice-based approaches that can speak to the cultural diversity of young people across the world. Finally, we are likewise interested in receiving original manuscripts that focus on the life and experiences of Indigenous youth around the world and how policy and institutions affect their lives to continue to build upon this most important scholarly literature. We believe these are important approaches, frameworks and issues that need to be discussed and debated within a robust youth studies scholarship.

As well as welcoming original research manuscripts, we are also interested in publishing book reviews on youth studies' scholarship. This first issue contains two book reviews on analysis of youth transitions for working-class men (Johnston) and an examination of the promise of higher education in a post-truth era (Dadvand). We see 
the function of book reviews as spaces to initiate or continue debates and dialogues on issues that matter to youth studies research. That is, book reviews should not just aim to summarise contemporary book manuscripts but contribute to the field by constructing or moving forward the research and/or practice agenda. We are also underway with some special issues and welcome suggestions for these by guest editors.

In these troubling times, we believe that as youth scholars, our research agenda should be focused on highlighting, analysing and explaining the challenges faced by contemporary young people across places and cultures and building a space for youth research debate and scholarship. This is the hope and the promise of the Journal of Applied Youth Studies.

\section{References}

Bendit R, Miranda A (2016) Turning thirty: youth transition processes in 21st century Argentina. Journal of Applied Youth Studies 1(3):96-108

Denny L, Churchill B (2016) Youth employment in Australia: a comparative analysis of labour force participation by age group. Journal of Applied Youth Studies 1(2):5-22

Lewin K (1976) Field theory in social science: selected theoretical papers. University of Chicago Press, Chicago, IL

Sercombe H (2015) The watchmaker's chainsaw: why new public management is the wrong tool for youth work (and most of the professions). Journal of Applied Youth Studies 1(1):97-121 